\title{
O PROCESSO DE APRENDIZAGEM E A GESTÃO DO CONHECIMENTO EM EMPRESAS MINEIRAS DE VANGUARDA
}

\author{
Maria Celeste Reis Lobo de Vasconcelos \\ Mestrado Profissional em Administração - Fundação Pedro Leopoldo \\ Marta Araújo Tavares Ferreira \\ Programa de Pós Graduação em Ciência da Informação - UFMG
}

\section{RESUMO}

O conhecimento tem sido reconhecido como sendo um dos principais recursos estratégicos das empresas no mundo atual e, em conseqüência, a aprendizagem tem sido considerada como sendo o processo mais importante. As empresas mais inovadoras e competitivas são aquelas que desenvolvem a habilidade de gerenciar o conhecimento, incorporando-o aos seus produtos e serviços. Dentro deste cenário, a gestão do conhecimento e a implementação de uma cultura da aprendizagem devem estar inseridas no conjunto de estratégias das empresas. Mas qual é a realidade das empresas brasileiras em relação a estas questões? Este artigo propõe uma sistemática para avaliar a gestão do conhecimento e a aprendizagem nas empresas e analisa o comportamento de empresas mineiras frente a estas práticas, focalizando as pequenas e médias empresas (PME).

\section{INTRODUÇÃO}

Por que algumas empresas têm maior capacidade de inovação do que outras? Para NONAKA \& TAKEUCHI (1997) a criação do conhecimento organizacional representa a chave para que as empresas inovem de forma contínua. Para LEONARD BARTON (1998) as empresas mais inovadoras são as que demonstram maior competência para gerar e administrar conhecimentos. DAVENPORT \& PRUSAK (1998) acrescentam que as empresas mais bem sucedidas são aquelas onde a gestão do conhecimento faz parte do trabalho de todos os seus membros. CHOO (1998) afirma que as empresas que sobrevivem no mercado globalizado têm o conhecimento como principal recurso estratégico. EDVINSSON \& MALONE (1998) ressaltam que as empresas são cada vez mais valorizadas pelos seus ativos intangíveis, que são ativos que não possuem existência física e por isto são de difícil avaliação. Para THUROW (1997) as empresas mais inovadoras são aquelas que estão derrubando as paredes funcionais e permitindo que as decisões sejam tomadas nos níveis mais baixos da organização. Os empregados precisam ser mais bem qualificados e a gerência, principalmente a situada no topo das organizações, deve ser capaz de comunicar a todos os subordinados as estratégias da empresa, de forma que aqueles que estão nos níveis hierárquicos inferiores possam tomar decisões alinhadas às mesmas.

A gestão do conhecimento assume, pois, um elevado grau de relevância para as empresas de todos os setores da economia. Observa-se que as iniciativas de gestão do conhecimento demandam profissionais que tenham facilidade em gerir relacionamentos com equipes internas e externas e com fornecedores externos da informação e do conhecimento, tais como clientes, outras empresas e parceiros acadêmicos. Mas, para gerir este conhecimento, é fundamental a identificação exata da localização do conhecimento nas empresas.

\section{LOCALIZAÇÃO DO CONHECIMENTO NAS EMPRESAS}

NONAKA \& TAKEUCHI (1997) chamam atenção para o fato das empresas japonesas entenderem o conhecimento de forma bem diferente das empresas ocidentais. Eles defendem que o conhecimento expresso em palavras e números, denominado de conhecimento explícito, representa 
apenas uma ponta de um iceberg. Eles entendem que o conhecimento é basicamente tácito, isto é, algo altamente pessoal. Segundo os autores, o conhecimento explícito pode ser facilmente processado por um computador, transmitido eletronicamente e armazenado em bancos de dados. Entretanto a natureza subjetiva e intuitiva do conhecimento tácito dificulta o seu processamento ou a sua transmissão por qualquer método sistemático ou lógico. Para que possa ser comunicado e compartilhado dentro da organização, o conhecimento tácito tem que ser convertido em palavras ou números que qualquer um possa compreender. É exatamente durante esse processo de conversão de tácito para explícito que o conhecimento organizacional é criado. Os estudos de NONAKA \& TAKEUCHI (1997) abriram novos caminhos para a compreensão da localização do conhecimento nas empresas e por conseqüência, sobre a dinâmica de criação do conhecimento.

Observa-se que novos termos foram criados para identificar e nomear o patrimônio de conhecimento das empresas. STEWART (1998) introduziu o conceito de "capital intelectual" como sendo a soma do conhecimento de todos em uma empresa, o que lhe proporciona vantagem competitiva. Para ele, gerenciar o capital intelectual deve ser a prioridade número um de uma empresa. Para EDVINSSON \& MALONE (1998) o capital intelectual é o capital originário do conhecimento, representado por ativos não financeiros, que são os ativos intangíveis e ocultos de uma empresa.

Portanto, para que o conhecimento produza vantagem competitiva sustentável, ele precisa ser gerenciado de forma pró-ativa pelas empresas. Para GRATTON (2000), as empresas precisam colocar as pessoas no coração da estratégia como única maneira de serem competitivas. Na era do conhecimento, as partes mais valiosas dos trabalhos tornaram-se essencialmente tarefas humanas como sentir, julgar, criar e desenvolver relacionamentos. O trabalhador do conhecimento leva suas ferramentas consigo: em seu cérebro (STEWART, 1998).

\section{AVALIANDO O PROCESSO DE APRENDIZAGEM NAS EMPRESAS}

KIM (1998) se dedicou ao estudo do processo através do qual a aprendizagem individual promove a aprendizagem organizacional. Para o autor, a aprendizagem organizacional é algo bastante complexo e dinâmico não se constituindo unicamente de uma ampliação da aprendizagem individual. Fica claro que uma organização aprende através de seus membros individuais e por conseqüência é afetada direta ou indiretamente pela aprendizagem individual.

Segundo JASHAPARA, (1993), organizações competitivas pela aprendizagem são organizações que se adaptam continuamente, que promovem a aprendizagem focalizada nos níveis individual, de equipe e organizacional, satisfazendo as necessidades sempre mutantes dos clientes, entendendo a dinâmica das forças competitivas e encorajando o pensamento sistêmico, que SENGE (1990) chama de quinta disciplina, dentro do conjunto de disciplinas necessárias à constituição da aprendizagem nas organizações. Em sua análise sobre as organizações de aprendizagem, SENGE (1990) focaliza primeiramente o processo de aprendizagem do indivíduo, passando para o grupo e finalmente para a organização:

Devido ao relevante papel desempenhado pela aprendizagem no contexto atual, alguns autores têm preferido denominar esta nova fase da economia de Economia da Aprendizagem (LASTRES \& FERRAZ, 1999).

FLEURY (1995) descreve alguns pontos essenciais para gerar a dinâmica de aprendizagem na empresa: o processo de inovação e de busca contínua de capacitação e qualificação das pessoas, 
o processo de aprendizagem que deve ser um processo coletivo e a comunicação, que deve fluir entre pessoas, áreas, níveis, visando à criação de competências interdisciplinares.

A preocupação dos autores citados com a aprendizagem nos três níveis da organização ressalta a importância do processo de aprendizagem na acumulação da capacitação tecnológica da empresa. Numa organização aprendiz todos os membros participam e contribuem para a gestão do conhecimento.

\section{PRINCIPAIS ETAPAS DA GESTÃO DO CONHECIMENTO}

Com base nos itens anteriores, é possível diferenciar 3 momentos importantes do processo de gestão do conhecimento: aquisição e geração do conhecimento; disseminação, compartilhamento e transferência do conhecimento; codificação do conhecimento ou construção da memória.

\section{AQUISIÇÃO E GERAÇÃO DO CONHECIMENTO}

Esta etapa inclui o conhecimento adquirido por uma organização e também o conhecimento que ela desenvolve. O conhecimento adquirido não precisa ser necessariamente recém criado, mas apenas ser novidade para a organização. As empresas têm procurado enfatizar, através da criação de prêmios, a importância do conhecimento adquirido. Ressalta-se nesta categoria o prêmio "Ladrão do Ano" criado pela British Petroleum e concedido às melhores idéias no desenvolvimento de aplicativos e o prêmio "Não foi inventado aqui mas foi eu que consegui" criado pela Texas Instruments (DAVENPORT \& PRUSAK, 1998).

Para LEONARD BARTON (1998), a geração do conhecimento introduz complexidade e até mesmo conflito para criar uma nova sinergia. A autora chama a este processo de abrasão criativa, que descreve a maneira como a combinação deliberada de pessoas com diferentes habilidades, idéias e valores podem gerar soluções criativas: A inovação ocorre nas fronteiras entre as mentes, não dentro do território provinciano de uma só base de habilidades e conhecimento. Portanto, as mentes precisam entrar em contato para que as fronteiras possam existir.

Para NONAKA \& TAKEUCHI (1997) o sucesso das empresas japonesas está fortemente ligado à sua capacidade na criação do conhecimento organizacional, que representa a capacidade da empresa em criar novo conhecimento, difundi-lo na organização como um todo e incorporá-lo a produtos, serviços e sistemas. O conhecimento obtido externamente também é compartilhado de forma ampla dentro da organização, armazenado como parte da base de conhecimentos da empresa e utilizado pelos envolvidos no desenvolvimento de novas tecnologias e produtos. Esta dupla atividade, interna e externa, é que abastece a inovação contínua dentro das empresas. A inovação contínua, por sua vez, leva a vantagens competitivas através das etapas criação do conhecimento, inovação contínua e vantagem competitiva. Os autores ressaltam que a aprendizagem precisa ocorrer em todos os níveis da organização. Desta forma, habilidades e conhecimentos vão se transformando em competências, através dos verbos mobilizar, participar, aprender, comprometer. O conhecimento só pode ser criado por indivíduos e a organização precisa apoiar os indivíduos criativos e lhes proporcionar contextos para a criação do conhecimento.

\section{DISSEMINAÇÃO, COMPARTILHAMENTO E TRANSFERÊNCIA DO CONHECIMENTO}

E como se transfere o conhecimento? Apesar de se ouvir através da mídia que o processo de globalização e a disseminação das tecnologias da informação e comunicação permitem a fácil transferência de conhecimento, observa-se que, ao contrário dessa tese, apenas informações e algum conhecimento podem ser facilmente transferíveis. Elementos cruciais do conhecimento, implícitos 
nas práticas de pesquisa, desenvolvimento e produção, não são facilmente transferíveis pois estão enraizados em pessoas, organizações e locais específicos. Somente quem tem este tipo de conhecimento é capaz de gerar inovações em produtos, processos e formas organizacionais. Assim enormes esforços têm sido realizados para tornar novos conhecimentos apropriáveis, bem como para estimular a interação entre os diferentes agentes econômicos e sociais visando a geração de inovações (LEMOS, 1999).

Gerentes do conhecimento bem sucedidos perceberam que o conhecimento é transferido através de múltiplos canais que se reforçam mutuamente. Os parceiros precisam se reunir regularmente num ambiente que possibilite o contato face a face. DAVENPORT \& PRUSAK (1998) alertam que o compartilhamento do conhecimento exige confiança. Deve ser estimulado e recompensado e que o suporte da direção e recursos financeiros são fatores essenciais. Para os autores, a melhor maneira de uma organização transferir conhecimentos é contratar pessoas perspicazes e deixar que elas conversem entre si. Na economia regida pelo conhecimento, conversar é trabalhar. As reuniões face a face são de longe os mais importantes canais de transferência de tecnologia pois a transferência de conhecimento tácito geralmente exige intenso contato pessoal.

GRATTON (2000) também é da opinião que a confiança é fundamental nos processos de transmissão de conhecimentos. Os indivíduos precisam confiar uns nos outros e também na empresa para começar a trocar informações. A criação deste ambiente de confiança leva tempo e precisa ser estimulado pela empresa. Neste processo, o papel da comunicação é crucial.

\section{CODIFICAÇÃO DO CONHECIMENTO OU CONSTRUÇÃO DA MEMÓRIA}

O objetivo da codificação é apresentar o conhecimento numa forma que o torne acessível àqueles que precisem dele. As tecnologias da informação e comunicações permitem uma maior codificação do conhecimento e, portanto, aceleram o processo de inovação e mudança tecnológica. Mas alguns tipos de conhecimento não podem ser efetivamente codificados, pelo menos por escrito. POLANYI (1983) lembra que é quase impossível reproduzir, num banco de dados ou documento, o conhecimento tácito: tente explicar em detalhes como nadar ou andar de bicicleta.

Para FLEURY \& FLEURY (2000) a construção da memória organizacional refere-se ao processo de armazenagem de informações com base na história organizacional e deve incluir todas as experiências, tanto as bem sucedidas quanto as mal sucedidas. Todas estas informações podem auxiliar na tomada de decisões.

\section{REALIZAÇÃO DA PESQUISA DE CAMPO}

Buscou-se nesta pesquisa avaliar as práticas de gestão do conhecimento e a aprendizagem nas empresas à luz das contribuições mais recentes sobre a natureza do conhecimento, da inovação, da gestão do conhecimento e da aprendizagem organizacional. $\mathrm{O}$ trabalho teve o objetivo de analisar o comportamento de empresas mineiras em relação a estas questões, ressaltando as pequenas e médias empresas.

Para avaliar se as empresas que responderam à pesquisa têm características de organizações "que aprendem" ou organizações "competitivas"; foi selecionado, com base na literatura, um conjunto de quesitos considerados hoje como fundamentais para a efetiva gestão do conhecimento nas empresas. Para efeito de análise, os resultados foram agrupados nas três etapas características do processo de gestão do conhecimento, que são: aquisição e geração do conhecimento, disseminação, compartilhamento e transferência do conhecimento e codificação do conhecimento e construção da 
memória.

A metodologia utilizada na pesquisa de campo foi o survey com propósito exploratório e o instrumento de pesquisa foi o questionário. O questionário foi composto de 36 questões, na maioria de múltipla escolha, dispostas em 6 (seis) blocos distintos. Este artigo focalizou apenas os blocos de 2 a 5 do questionário que se referem a temas relacionados à gestão do conhecimento e à aprendizagem nas empresas, à luz da revisão bibliográfica. O questionário completo foi utilizado para outras pesquisas (VASCONCELOS, 2000).

O survey foi realizado entre as empresas participantes de um programa de parceria entre o setor industrial mineiro e as universidades, com foco na pós-graduação. O Programa estimula a cooperação entre o setor de pesquisa e o setor privado e foi escolhido para análise pelo fato de ser regional, único no gênero, unindo governo, setor empresarial e setor de pesquisa, na busca da melhoria da competitividade da indústria mineira e no conseqüente desenvolvimento do estado de Minas Gerais. A população estudada foi constituída de 91 empresas, tendo sido recebidas 56 respostas.

\section{RESULTADOS}

Com base nas respostas obtidas pela pesquisa de campo e na literatura, foi possível fazer algumas reflexões sobre o estágio atual da gestão do conhecimento e da dinâmica de aprendizagem nas empresas estudadas.

\section{Caracterização das empresas}

A análise das informações recebidas das empresas revelou uma amostra bastante interessante em relação à distribuição setorial, ao porte, à origem do capital, ao âmbito de atuação, à posição no mercado e aos fundamentos da estratégia.

\section{Distribuição setorial}

A distribuição por setor industrial das 56 empresas que responderam à pesquisa mostrou uma grande diversidade de setores de atuação, 27 no total. Observou-se uma predominância de empresas do setor de alimentos e bebidas, representando $21,3 \%$ do total; em seguida, vieram os setores de siderurgia $(9,8 \%)$, mineração $(8,2 \%)$ e florestal $(4,9 \%)$.

\section{Porte}

Como mostrado na TAB. 1, as empresas foram divididas em quatro categorias de acordo com o número de empregados. $18 \%$ das empresas possuem menos de 19 empregados, $16 \%$ possuem entre 20 e 99 empregados, 36\% possuem de 100 a 499 empregados e $30 \%$ possuem mais de 500 empregados. Quando comparadas às 500 maiores empresas da revista EXAME - Melhores e Maiores (2000), os dados mostram que 16 (dezesseis) empresas respondentes fazem parte dessa relação e 3 (três) delas inclusive estão na lista das "100 melhores empresas para se trabalhar", da própria EXAME (2000).

TABELA 1: Distribuição por Porte, segundo CNI (1997)

\begin{tabular}{lcc}
\hline \multicolumn{1}{c}{ PORTE } & N $^{\circ}$ EMPRESAS & $\%$ \\
\hline MICRO (até 19 empregados) & 10 & $18 \%$ \\
PEQUENA (de 20 a 99 empregados) & 9 & $16 \%$ \\
MÉDIA (de 100 a 499 empregados) & 20 & $36 \%$ \\
GRANDE (acima de 500 empregados) & 17 & $30 \%$ \\
\hline \hline
\end{tabular}




\section{Origem do capital}

Conforme mostrado na FIG. 1, 64\% das empresas são de capital totalmente nacional privado; $18 \%$ majoritariamente nacional privado; $6 \%$ de capital totalmente estrangeiro; $8 \%$ majoritariamente estrangeiro e $4 \%$ estatais. No caso das PME, das 36 empresas que forneceram essa informação, 83 $\%$ são de capital totalmente nacional, $6 \%$ de capital majoritariamente nacional, $3 \%$ estatal e $8 \%$ de capital majoritariamente estrangeiro.

Se considerarmos como "empresas nacionais" aquelas com capital totalmente nacional e majoritariamente nacional, e como "estrangeiras" aquelas com capital majoritariamente estrangeiro ou totalmente estrangeiro, obtemos a seguinte distribuição: nacionais $86 \%$ e estrangeiras $14 \%$. No caso das PME, chegamos à proporção de $92 \%$ de empresas nacionais e apenas $8 \%$ de empresas estrangeiras. Esta distinção é considerada relevante por FLEURY \& FLEURY (2000) a partir do pressuposto de que as empresas com capital nacional e majoritariamente nacional possuem centros de decisão locais, enquanto aquelas com capital majoritariamente estrangeiro têm centros de decisão no exterior.

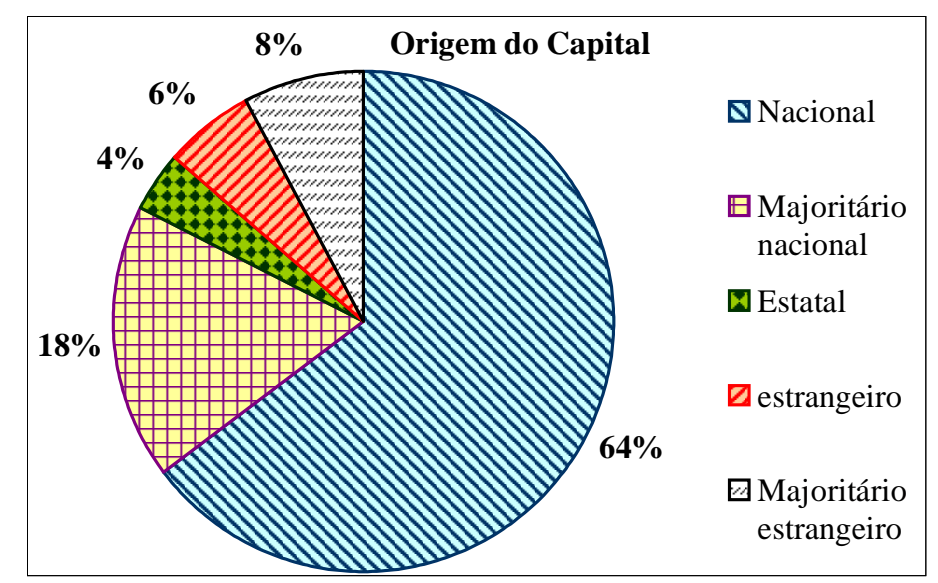

\section{FIGURA 1 - CLASSIFICAÇÃO DAS EMPRESAS SEGUNDO A ORIGEM DO CAPITAL (52 EMPRESAS RESPONDERAM)}

\section{Âmbito de atuação}

Quanto ao âmbito da atuação, 33\% das empresas afirmam ter atuação global, $8 \%$ têm atuação no âmbito do Mercosul, $47 \%$ têm atuação em todo o território nacional e apenas $12 \%$ têm atuação apenas no âmbito local, ou seja em MG (FIG. 2). 


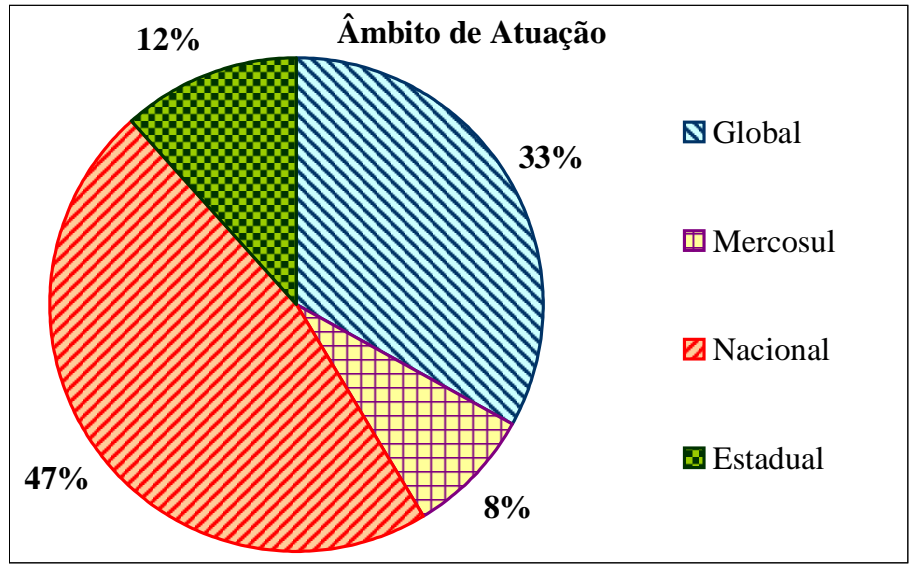

\section{FIGURA 2 - ÂMBITO DE ATUAÇÃO DAS EMPRESAS (52 EMPRESAS RESPONDERAM)}

\section{POSIÇÃO DAS EMPRESAS NO MERCADO}

De acordo com as respostas recebidas a esta questão, 64\% das empresas ocupam a liderança do mercado de seu principal produto, $23 \%$ ocupam a segunda posição e apenas $13 \%$ ocupam a terceira posição ou inferior (FIG. 3).

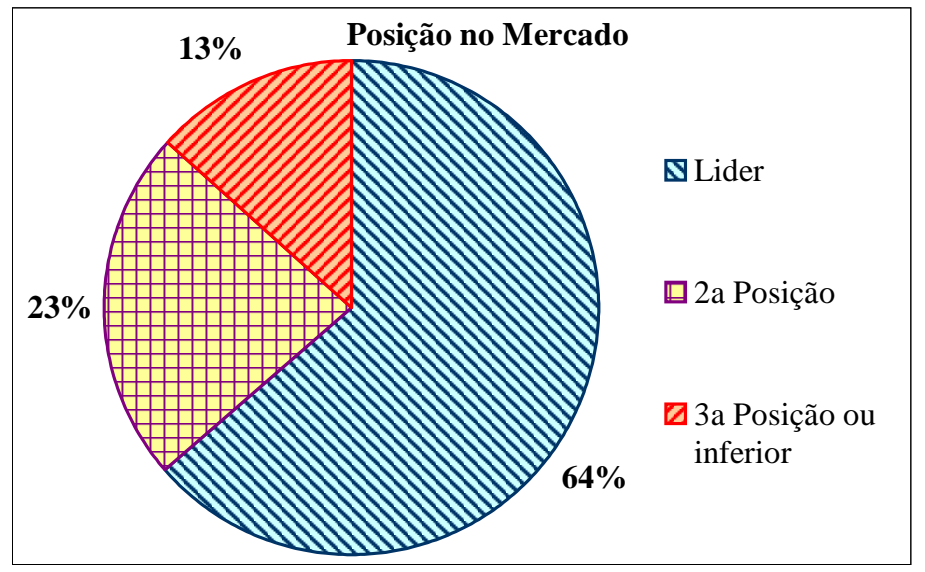

\section{FIGURA 3 - POSIÇÃO NO MERCADO DOS PRODUTOS DAS EMPRESAS (53 EMPRESAS RESPONDERAM)}

Considerando-se apenas as PME (36 respostas), 58\% são líderes no mercado de seu principal produto, $28 \%$ ocupam a segunda posição e $14 \%$ a terceira posição ou posição inferior, resultados ligeiramente inferiores aos obtidos pelo conjunto das empresas.

\section{FUNDAMENTOS DA ESTRATÉGIA}

Em relação à estratégia adotada pelas empresas na venda dos seus produtos, encontramos a distribuição mostrada na FIG. 4 para os fatores de competitividade. É importante ressaltar que foi dada aos respondentes a possibilidade de responder a mais de um fator, fazendo com que a soma das porcentagens ultrapasse os $100 \%$.

Qualidade: $84 \%$

Preço: $31 \%$

Inovação: $18 \%$

Canais de distribuição:13\%

Falta de concorrência: 9\% 
Design: $9 \%$

Publicidade: $7 \%$

Outros: (credibilidade, assistência ao cliente, divulgação em congressos): $11 \%$.

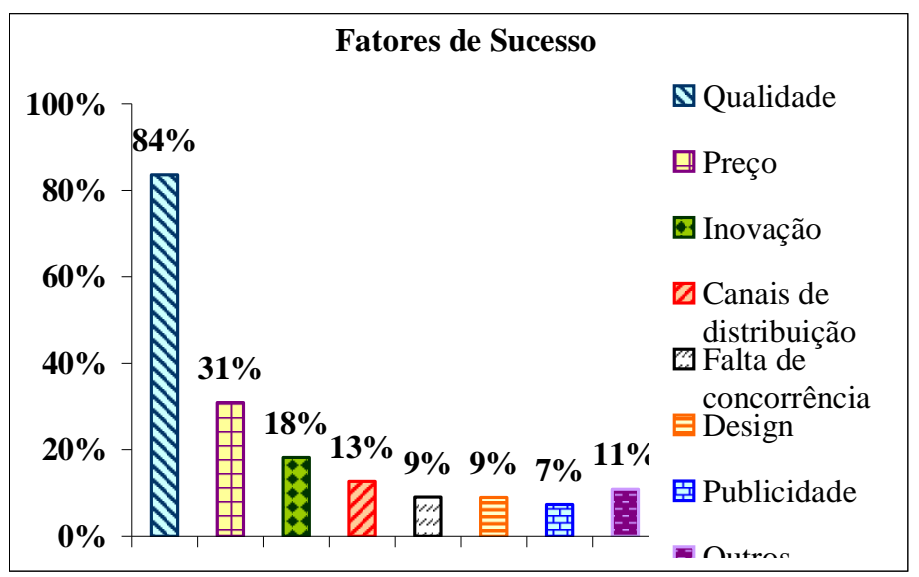

FIGURA 4 - FATORES DE SUCESSO DAS EMPRESAS

Esta distribuição coincide com os resultados obtidos por outros estudos (FLEURY, 1995; FLEURY \& FLEURY, 2000; CNI, 1997) que indicaram os fatores qualidade e preço como sendo os principais fundamentos das estratégias das empresas brasileiras na busca da competitividade, seguidas pela inovação e logística de distribuição.

Quanto às empresas (no total de 10) que citaram a inovação como fator de competitividade, destacase o fato de que 9 delas são líderes do mercado.

\section{CONCLUSÕES QUANTO AO PERFIL DAS EMPRESAS}

Com base nas informações obtidas, considera-se que as empresas estão engajadas no grande desafio de serem competitivas numa economia globalizada e têm as características:

a) empresas oriundas de mais de 20 diferentes setores industriais,

b) micro, pequenas, médias e grandes empresas, sendo que a maior parcela, de $36 \%$, é composta de médias empresas e a segunda maior, de $30 \%$, é de grandes,

c) $86 \%$ são empresas nacionais e apenas $14 \%$ "estrangeiras",

d) a maior parcela, de $47 \%$, atua apenas em nível nacional e uma outra parcela, também muito representativa, de $36 \%$, atua no nível global,

e) $60 \%$ são líderes de mercado em relação ao seu principal produto,

f) buscam a qualidade $(84 \%)$ como principal fator de competitividade, seguida pelo preço (31\%), a inovação (18\%) e a logística de distribuição (13\%).

Nas próximas seções, foram feitas algumas análises sobre as formas utilizadas por estas empresas na gestão do conhecimento e na criação de uma cultura de aprendizagem.

\section{GESTÃO DO CONHECIMENTO NAS EMPRESAS PESQUISADAS: QUESTÕES SELECIONADAS}

Para avaliar se as empresas que responderam à pesquisa têm características de organizações "que aprendem" ou organizações "competitivas"; foi selecionado, com base na literatura, um conjunto de quesitos considerados hoje como fundamentais para a efetiva gestão do conhecimento nas empresas. Neste conjunto estão incluídas questões que têm o objetivo de verificar se as empresas 
estão concentrando esforços na criação de um ambiente de aprendizagem, aspecto fundamental para que os funcionários contribuam para o crescimento da empresa, dêem sugestões, sejam criativos, interajam com os outros membros da equipe, tratem melhor o cliente e, portanto, façam a empresa prosperar.

São listadas abaixo as questões selecionadas para analisar cada uma das 3 etapas características da gestão do conhecimento e as justificativas de sua escolha com base na literatura. Alguns dos quesitos selecionados atendem a mais de uma das etapas mas foram incluídos em apenas uma para efeito de análise.

\section{AQUISIÇÃO E GERAÇÃO DO CONHECIMENTO}

As perguntas selecionadas versaram sobre o desenvolvimento de competências através de treinamento, o incentivo à participação dos empregados com idéias e sugestões na melhoria de processos e produtos, a abrangência do processo de aprendizagem, a relação da empresa com o ambiente externo e a postura explícita da empresa em relação à criação do conhecimento. A justificativa da escolha dos quesitos, com base na literatura, está desenvolvida a seguir.

a) política de treinamento da empresa: observa-se um novo desafio nas organizações no sentido de desenvolver instrumentos capazes de despertar a criatividade dos funcionários assim como mantê-los atualizados, de forma a apoiar o processo de inovação. As empresas têm dado apoio para que os funcionários se desenvolvam, o que só é possível se houver investimentos consistentes em treinamento.

b) incentivo à participação dos empregados: a valorização das boas idéias e o incentivo à criatividade tem sido considerados pontos fundamentais para a etapa de criação de conhecimento nas empresas. A adoção de medidas para a participação dos empregados, como as tradicionais caixas de sugestões, reuniões periódicas com a direção da empresa, ações tipo "portas abertas ao presidente", entre outras, representa uma estratégia da empresa em desenvolver propostas de melhoria contínua e aprendizagem entre os funcionários. (FLEURY \& FLEURY, 2000).

c) processo de aprendizagem: vários autores (NONAKA \& TAKEUCHI, 1997, LASTRES \& FERRAZ, 1999, COHEN, 1999) apostam na aprendizagem como processo central na geração de conhecimentos. O principal resultado do processo de aprendizagem é a capacidade de inovação e de criação de conhecimento tácito ou explícito. Alguns têm ressaltado a importância de uma abordagem sistêmica e interativa do processo de aprendizagem (SENGE, 1990, JASHAPARA, 1993, FLEURY, 1995).

d) relação da empresa com o ambiente externo: esta é uma das principais facetas da gestão do conhecimento, que deve harmonizar relacionamentos entre equipes internas e externas. Esta dupla atividade, interna e externa, é uma importante forma de abastecer a inovação contínua, que por sua vez, leva a vantagens competitivas. As principais fontes externas de conhecimento são os clientes, os fornecedores, as outras empresas e os parceiros acadêmicos (LEONARD BARTON, 1998, NONAKA \& TAKEUCHI, 1997).

\section{DISSEMINAÇÃO, COMPARTILHAMENTO E TRANSFERÊNCIA DO CONHECIMENTO}

As perguntas selecionadas para avaliar esta etapa incluíram a sistemática de elaboração da estratégia, o processo de tomada de decisão, a eficiência na comunicação interna, a estrutura organizacional e a postura explícita da empresa em relação ao compartilhamento do conhecimento. Segundo a literatura, estes fatores contribuem para a criação de um bom ambiente de trabalho, onde os funcionários se sintam parte de um único time e com isto se sintam seguros para o compartilhamento do conhecimento. 
a) sistemática de elaboração da estratégia: FLEURY \& FLEURY (2000) ressaltam a importância da participação dos funcionários no processo de elaboração de estratégias como forma de se obter adesão. Neste ambiente organizacional, todos os empregados sabem aonde a empresa quer chegar, seus planos, números, estratégias e metas. Há consenso quanto aos pontos fortes e pontos para melhoria da empresa. Para TERRA (2000) a liderança não deve ditar a estratégia, mas promover o pensamento estratégico.

b) processo de tomada de decisão: representa uma parte vital das organizações uma vez que todas as ações se iniciam por uma tomada de decisão. A liberdade de decisão e ação para as pessoas, incluída no processo de empowerment representa um estímulo à iniciativa e à criatividade. A necessidade de se criar conhecimento numa base contínua envolve, portanto, a descentralização do processo de tomada de decisão.

c) processo de comunicação interna: representa um dos pontos essenciais, para gerar a dinâmica de aprendizagem nas empresas. Para JASHAPARA (1993) a aprendizagem estendida a todos os níveis da empresa é, em grande parte, resultado da comunicação efetiva e de sistemas de distribuição de informação. Na revista EXAME (2000), a clareza e abertura na comunicação interna foram quesitos analisados para escolha das empresas eleitas. A comunicação eficiente gera confiança.

d) estrutura organizacional: A implementação de novas formas organizacionais tem sido um desafio permanente para as empresas na busca de novos padrões de relacionamento entre a alta administração, media gerência e demais funcionários. As novas estruturas facilitam a aproximação entre chefes e subordinados, aumentando a interação e eliminando barreiras, facilitando o processo de compartilhamento.

\section{CODIFICAÇÃO DO CONHECIMENTO E CONSTRUÇÃO DA MEMÓRIA}

As perguntas selecionadas para avaliar esta etapa incluíram o desenvolvimento de sistemas de informação, a forma de utilização dos resultados dos treinamentos e os esforços para registro explícito do conhecimento.

a) sistema de informação: segundo STEWART (1998), os sistemas de informação representam ativos intelectuais estruturais que são responsáveis pela transformação do know how individual em propriedade de um grupo. Esses ativos estruturais vão dar suporte ao compartilhamento, transmissão e alavancagem de conhecimentos. A eficiente gestão dos sistemas de informação para inovação é apontada por LASTRES (1996) como sendo um dos fatores de sucesso das empresas japonesas.

b) documentação e compartilhamento do resultado do treinamento: o investimento na capacitação e treinamento de recursos humanos não basta. Tão importante como os esforços de treinamento devem ser os esforços de compartilhamento e documentação do conhecimento adquirido ou desenvolvido (TERRA, 2000).

\section{GESTÃO DO CONHECIMENTO NAS EMPRESAS PESQUISADAS: RESULTADOS DA PESQUISA}

\section{Aquisição e geração do conhecimento.}

A pesquisa mostrou que:

a) política de treinamento da empresa:

$>51 \%$ das empresas responderam que existe preocupação da administração no sentido de que todos tenham algum tipo de treinamento ( $57 \%$ no caso das PME).

$>24 \%$ responderam que a empresa prioriza a capacitação de pessoal a ponto de dedicar mais de $5 \%$ da carga horária de cada empregado ao treinamento (15\% nas PME). 
> $14 \%$ responderam que o treinamento dos empregados não é planejado e é normalmente associado à sua área de trabalho (15\% no caso das PME).

$>4 \%$ responderam que a empresa não tem uma política de capacitação de pessoal e que não há treinamentos apoiados pela empresa (5\% no caso das PME).

$>7 \%$ não responderam esta questão ( $8 \%$ no caso das PME).

b) incentivo à participação dos empregados:

$>60 \%$ responderam que os empregados contribuem, de forma aleatória, com idéias e sugestões para a melhoria dos processos e/ ou produtos ( $72 \%$ no caso das PME).

$>29 \%$ responderam que a empresa dispõe de esquema organizado que permite a todos os funcionários contribuírem com idéias e sugestões (18\% no caso das PME).

$>6 \%$ responderam que as contribuições dos empregados são mínimas (5\% das PME).

$>5 \%$ não responderam esta questão (5\% das PME).

c) processo de aprendizagem:

> $62 \%$ dos pesquisados são da opinião que o processo de aprendizagem na empresa é um processo coletivo, partilhado por todos e não privilégio de uma minoria pensante. A aprendizagem dos funcionários é também estimulada através da ampliação dos contatos com outras pessoas de dentro e fora da empresa (59 \% no caso das PME).

$>26 \%$ responderam que a preocupação com a aprendizagem está concentrada em alguns níveis da empresa e não constitui um processo sistêmico (28 \% no caso das PME).

$>4 \%$ responderam que a aprendizagem está restrita a iniciativas isoladas dos funcionários (3\% das PME).

$>8 \%$ não responderam a esta questão (10\% no caso das PME).

d) relação da empresa com o ambiente externo:

> 75\% acham que a empresa olha para fora e para o futuro, prevendo mudanças no mercado, na tecnologia, na concorrência ou no produto. A empresa está atenta aos seus fornecedores, clientes, distribuidores, órgãos governamentais e até concorrentes em busca de novas idéias. Além disto, a empresa monitora sistematicamente patentes, concorrentes e outras fontes de conhecimento (74\% das PME).

$>16 \%$ responderam que não há atividade sistemática de monitoria do ambiente tecnológico (18\% das PME).

$>4 \%$ responderam que a monitoração de patentes e outras fontes de conhecimento é realizada por iniciativa de alguns funcionários e não constitui uma política da empresa (3\% das PME).

$>5 \%$ não responderam esta questão (5\% das PME).

e) manifestação explícita de criação do conhecimento:

$>35 \%$ são da opinião que a empresa se encontra na fase de tentar criar ambientes que convertam o conhecimento pessoal dos empregados em conhecimento explícito, que possa promover a inovação e o desenvolvimento de novos produtos (31\% das PME).

$>31 \%$ acreditam que o sucesso da empresa está na sua capacidade em criar novo conhecimento e difundi-lo na organização como um todo, resultando em constantes inovações em seus produtos, serviços e sistemas gerenciais (33\% das PME).

$>18 \%$ acreditam que o sucesso da empresa está na sua capacidade em transferir e adaptar conhecimentos e não na criação do conhecimento (23\% das PME).

$>9 \%$ responderam que, embora a empresa valorize a capacidade de criar e transferir conhecimentos, o sucesso da empresa não está baseado nestas áreas (8\% das PME).

$>7 \%$ não responderam esta questão (5\% das PME).

\section{DISSEMINAÇÃO, COMPARTILHAMENTO E TRANSFERÊNCIA DO CONHECIMENTO}

A pesquisa mostrou que: 
a) sistemática de elaboração da estratégia

$>53 \%$ (46\%, no caso das PME) responderam que as respectivas empresas elaboram suas estratégias de forma participativa e sistemática e que há consenso quanto aos seus pontos fortes e pontos para melhoria. Além disso, na visão dos respondentes, a missão da empresa é compreendida por todos.

$>24 \%$ (31\% das PME) responderam que a empresa elabora sua estratégia de forma sistemática. Há preocupação com a divulgação dos seus pontos fortes e pontos para melhoria. A missão é divulgada por escrito.

$>16 \%$ (15\% das PME) responderam que o planejamento não é participativo. A empresa é dirigida pela alta administração. As metas só são compartilhadas nos níveis superiores da hierarquia.

$>4 \%$ (5\% das PME) responderam que não há elaboração formal da estratégia da empresa.

$>3 \%$ (também 3\% no caso das PME) não responderam a esta questão.

b) processo de tomada de decisão

$>49 \%$ (54\% das PME) responderam que o processo decisório nas empresas é ágil e a burocracia é mínima. As gerências comunicam a todos as estratégias da empresa, para que os níveis hierárquicos inferiores possam tomar decisões alinhadas às mesmas.

$>33 \%$ (28\% das PME) responderam que a média gerência tem autonomia para algumas decisões...

$>$ em $15 \%$ das empresas (15\% das PME) o processo decisório é bastante centralizado.

$>3 \%$ não responderam a esta questão.

c) processo de comunicação interna

$>51 \%$ das empresas (56\% das PME) testemunharam que, apesar da comunicação ser ainda deficiente, há um esforço para que ela flua entre pessoas, áreas, níveis, visando à criação de competências interdisciplinares.

$>42 \%$ (39\% das PME) são da opinião que a comunicação interna é eficiente e flui por toda a empresa.

$>2 \%$ das empresas $(0 \%$ PME) responderam que há pouca comunicação entre as áreas.

$>5 \%$ (também das PME) não responderam a esta questão.

d) estrutura organizacional

> 44\% (41\% das PME) responderam que a estrutura da empresa é claramente dividida por função (ex.: marketing, produção, vendas, assistência técnica, etc.).

$>33 \%$ (36\% das PME) responderam que as empresas estão buscando uma estrutura em redes horizontais, derrubando as paredes funcionais e criando uma "teia" entre invenção, projeto, fabricação, vendas, logística e serviços; que é característico das empresas avançadas.

$>14 \%$ (15\% das PME) responderam que a estrutura da empresa é baseada em projetos.

$>9 \%$ (8\% das PME) não responderam a esta questão.

e) manifestação explícita de compartilhamento do conhecimento:

> 46\% das empresas (também das PME) responderam que a empresa prioriza o on the job training. Os aprendizes aprendem com os seus mestres através da observação, imitação e prática. É incentivado que indivíduos troquem e combinem seus conhecimentos através de telefonemas, reuniões e memorandos.

$>27 \%$ (26\% das PME) responderam que a empresa disponibilizou recursos de correio eletrônico, internet, intranets e computadores em redes como forma de garantir o compartilhamento do conhecimento entre os seus funcionários.

$>16 \%$ (18\% das PME) responderam que a empresa acredita que o compartilhamento do conhecimento acontece de forma natural e aleatória entre os empregados.

$>11 \%$ (10\% das PME) não responderam a esta questão. 


\section{CODIFICAÇÃO DO CONHECIMENTO E CONSTRUÇÃO DA MEMÓRIA}

A pesquisa mostrou que:

a) sistemas de informação

$>42 \%$ (51\% das PME) responderam que tem sido feito um grande esforço pelas empresas no desenvolvimento de sistemas de informação.

$>26 \%$ (18\% das PME) responderam que as empresas dispõem de sistema de gestão integrada com informações gerenciais e operacionais para apoiar todas as decisões.

$>$ 26\% (23\% das PME) responderam que as empresas dispõem de sistemas de informação, apenas operacional, confiável e integrado e os funcionários acessam a informação através de base de dados.

$>3 \%$ (5\% das $\mid \mathrm{PME}$ ) responderam que as empresas não dispõem de sistemas de informação computadorizados e muito tempo é perdido em correções e verificações.

$>3 \%$ (3\% das PME) não responderam a esta questão.

b) documentação e compartilhamento do resultado do treinamento

> 35\% (38\% das PME) responderam que após cada treinamento, o funcionário tem de fazer um relatório descrevendo o conteúdo do curso e oportunidades. Dependendo do tipo de treinamento, o funcionário é convidado a fazer um relato sobre o assunto.

$>$ 35\% (31\% das PME) responderam que não há obrigatoriedade de expor o resultado do treinamento.

$>23 \%$ (23\% das PME) responderam que o conhecimento adquirido nos treinamentos é obrigatoriamente compartilhado dentro da empresa através de seminários, relatórios, bate papos, intranet e treinamentos internos.

$>\quad 7 \%$ (8\% das PME) não responderam esta questão.

c) manifestação explícita de registro do conhecimento

> 36\% (38\% das PME) declararam haver, na empresa, compreensão de que a gestão da inovação e do conhecimento tem hoje um elevado grau de importância para as empresas. Entretanto a empresa tem dificuldade em capturar o conhecimento através de seus sistemas, processos, produtos, regras e cultura.

$>33 \%$ (28\% das PME) responderam que a empresa tem um programa de gestão do conhecimento e que há rotinas estabelecidas para registro do conhecimento dos empregados e do know how existente na empresa.

$>16 \%$ (18\% das PME) responderam que a empresa ainda não se organizou para documentação do conhecimento.

$>8 \%$ (10\% das PME) responderam que a empresa apóia os indivíduos criativos e lhes proporciona ambiente para a criação do conhecimento, mas não busca registrar o conhecimento criado.

$>7 \%$ (6\% das PME) não responderam esta questão.

\section{CONCLUSÕES}

Os resultados obtidos indicam que a maioria das empresas estudadas (65\%) conta com ambientes propícios à criatividade ou está desenvolvendo ambientes favoráveis à aprendizagem, à inovação e ao desenvolvimento de novos produtos.

A maioria das empresas participantes da pesquisa (51\%) está, na opinião dos respondentes, consciente da importância do investimento em treinamento para todos os empregados como parte da gestão de recursos humanos e do esforço de geração de conhecimento. Ressalta-se o número significativo de empresas (23\%) que dedicam mais de 5\% do tempo de trabalho de cada empregado 
à sua formação. Isto equivale à cerca de 100 horas anuais, número bastante expressivo frente aos publicados por outros estudos similares.

É interessante observar que, na visão da maioria dos respondentes (61\%), o processo de aprendizagem nas respectivas empresas é um processo coletivo e sistêmico, partilhado por todos, condição essencial, para o crescimento das empresas.

No que toca ao compartilhamento do conhecimento, cerca de $46 \%$ dos respondentes acham que as empresas priorizam o on the job training, onde, segundo NONAKA \& TAKEUCHI (1997), os aprendizes aprendem com os seus mestres através de observação, imitação e prática. Nessas empresas os indivíduos são incentivados a trocar e combinar seus conhecimentos através de telefonemas, reuniões e memorandos.

Os resultados também apontam para a conscientização quanto à importância do trabalho participativo e do compartilhamento das informações. Cerca de 53\% responderam que as respectivas empresas elaboram suas estratégias de forma participativa, fator fundamental para se conseguir adesão e comprometimento.

Quanto ao processo decisório, $49 \%$ responderam que ele é ágil e a burocracia é mínima e há grande divulgação das estratégias das empresas, de modo a permitir que os níveis hierárquicos inferiores possam tomar decisões alinhadas às mesmas, fato característico de empresas avançadas. Cerca de $33 \%$ responderam que a média gerência tem autonomia para algumas decisões, sinalizando um inicio da descentralização do processo de tomada de decisão nessas empresas, necessário para a criação do conhecimento em base contínua.

As questões relativas à comunicação na empresa trouxeram resultados interessantes: enquanto $42 \%$ acreditam que a comunicação é eficiente em suas empresas e flui entre pessoas, áreas e níveis, uma parcela de $51 \%$ admite deficiências na comunicação mas declara já existir uma conscientização da sua importância na busca da criação de competências interdisciplinares, fator essencial para o estabelecimento de uma dinâmica de aprendizagem.

Verifica-se que a maioria das empresas (60\%) está desperdiçando uma enorme fábrica de idéias representada pelo aproveitamento das sugestões dos funcionários. Essas empresas não dispõem de nenhum esquema organizado para incentivar, coletar e utilizar as sugestões dos empregados para melhoria dos processos e produtos. Nessas empresas, os empregados contribuem com idéias de forma aleatória e espontânea. Apenas $29 \%$ das empresas indicaram que dispõem de esquemas organizados para a coleta de sugestões dos empregados. No entanto, FAULKNER, SENKER \& VELHO (1995) mostraram em suas pesquisas que 1/3 das informações usadas pelas indústrias na solução de problemas é proveniente dos conhecimentos dos próprios funcionários.

Além disso, os treinamentos podem ser mais bem aproveitados no âmbito das empresas. Apenas $24 \%$ das empresas responderam que o conhecimento adquirido nos treinamentos é obrigatoriamente compartilhado através de seminários, relatórios, bate papos, intranet e treinamentos internos. Em uma parcela significativa (35\%) não há obrigatoriedade de se expor os resultados dos treinamentos. Noutra parcela de $35 \%$ das empresas participantes, o funcionário só tem de fazer um relatório descrevendo o conteúdo do treinamento e as oportunidades percebidas. 
Apesar da maioria das respostas apontar a estrutura das empresas como sendo claramente funcional, observa-se que uma parcela bastante significativa (33\%) declara estar buscando estruturas organizacionais mais inovadoras, que buscam privilegiar a criatividade e a capacidade de aprendizagem através da interação entre os vários setores. Essas empresas estão buscando uma estrutura em redes horizontais, apoiadas no conceito de trabalho em equipe, o que é uma característica das empresas mais avançadas.

Quanto à codificação do conhecimento, cerca de $33 \%$ das empresas declararam dispor de rotinas estabelecidas para registro do conhecimento dos empregados e do know how existente na empresa. Entretanto, uma outra parcela superior (36\%) declarou ter dificuldade em capturar o conhecimento através de seus sistemas, processos, produtos, regras e cultura, o que, segundo MYERS (1996), representa a única forma do conhecimento produzir vantagem competitiva sustentável. Em uma pequena parcela (7\%) da amostra, a empresa apóia os indivíduos criativos e lhes proporciona ambiente para a criação do conhecimento, mas não busca registrar o conhecimento criado. Essas empresas não estão atentas ao desenvolvimento do capital estrutural, que é um dos componentes do capital intelectual da empresa.

O desenvolvimento de sistemas de informação ainda parece representar um desafio para as empresas. Entretanto, os resultados mostram preocupação e esforço (42\%) em solucionar esta questão. Cerca de $26 \%$ responderam que as empresas já dispõem de sistema de gestão integrada com informações gerenciais e operacionais para apoiar as decisões em todos os níveis. Outros $26 \%$ dispõem de sistema de informação apenas operacional. É importante lembrar que os sistemas de informação são ativos intelectuais do capital estrutural, que dão suporte ao compartilhamento, à transmissão e à alavancagem de conhecimentos.

Como visto na revisão bibliográfica, a gestão do conhecimento representa um conjunto de ações que visa orientar a empresa para a produção do bem mais valioso da nova economia, que é o conhecimento. Esta gestão visa descobrir formas de aproveitá-lo, difundi-lo, combiná-lo e de lucrar com ele. A análise da dinâmica de aprendizagem e de gestão do conhecimento das empresas participantes da pesquisa, mostrou que as empresas estão, em grande parte, comprometidas em criar ambientes propícios à gestão do conhecimento. Não se pode esquecer, entretanto, que todas as empresas participantes desta pesquisa fazem parte de um programa de cooperação entre universidades e empresas e, portanto, já estão sensibilizadas, a priori, para a importância do processo de inovação. Justifica-se desta forma seu maior empenho em facilitar os processos de geração, registro e compartilhamento de conhecimento.

Quanto à análise isolada das respostas fornecidas pelas PME da amostra (39 ao total), ela reproduziu em grande parte os resultados obtidos para o conjunto das empresas (56), indicando que, entre empresas sensibilizadas e engajadas no processo de inovação, como supomos serem as empresas estudadas nesta pesquisa, o tamanho não é uma barreira ao desenvolvimento de práticas e ambientes propícios aos processos de conhecimento. Resta-nos lembrar que as PME do grupo são em $92 \%$ dos casos nacionais, o que reforça a importância de uma tal constatação.

Apesar dos resultados bastante animadores, considera-se que ainda são grandes os desafios da indústria na busca da competitividade, pois a conversão de novos conhecimentos em novos produtos é um processo extremamente complexo. Toda inovação significativa é feita através de um longo caminho de contribuições provenientes de funcionários, usuários, empresas, universidades... 
De modo geral, as empresas precisam fortalecer os múltiplos canais de compartilhamento e de registro do conhecimento e aproveitar melhor os seus "patrimônios internos", representados pela experiência dos próprios funcionários. A criação deste ambiente de confiança leva tempo e precisa ser estimulada.

\section{REFERÊNCIAS BIBLIOGRÁFICAS}

1- .CHOO, C.W The knowing organization. Oxford: Oxford University Press, 1998.

2- COHEN, D. O fim do segredo. In: A GESTÃO da inteligência; como administrar a maior riqueza do futuro. Exame, A empresa do novo milênio n.3, São Paulo: Abril, 1999.

3- DAVENPORT, Thomas; PRUSAK, Laurence. Conhecimento empresarial: como as organizações gerenciam o seu capital intelectual. RJ: Campus, 1998. 237p.

4- EDVINSSON, L.; MALONE, M. S. Capital intelectual. São Paulo: Makron Books, 1998.

5- EXAME - As 100 melhores empresas para você trabalhar. São Paulo: Abril, ago. 2000.

6- FAULKNER, W.; SENKER, J.; VELHO, L. Knowledge frontiers: public sector research and industrial innovation in biotechnology, engineering ceramics, and parallel computing. New York: Oxford University Press, 1995. 337 p.

7- FLEURY, Afonso Aprendendo a mudar - aprendendo a aprender. Revista de Administração, São Paulo, v.30, n. 3, p.5-11, jul./ set. 1995.

8- FLEURY, A.; FLEURY, M. T. L. Estratégias empresariais e formação de competências; um quebra cabeça caleidoscópico da indústria brasileira. SP: Atlas, 2000. 169p.

9- GRATTON, Lynda. Palavras ao vento. Exame, São Paulo: Abril, p. 36-40, jul. 2000.

10-JASHAPARA, A. The competitive learning organization; a quest for the Holy Grail, Management Decision. v. 31, n. 8, p. 52-62, 1993.

11-KIM, D. H. O elo entre a aprendizagem individual e a aprendizagem organizacional, in: KLEIN, D. A gestão estratégica do capital intelectual: Recursos para a economia baseada no conhecimento, Rio de Janeiro: Qualitymark, 1998. 360 p.

12-LASTRES, H.; FERRAZ, João C. Economia da informação, do conhecimento e do aprendizado. In: LASTRES, H.; ALBAGLI, S. (Org.). Informação e globalização na era do conhecimento. Rio de Janeiro: Campus, 1999.

13-LEMOS, C. Inovação na era do conhecimento In: LASTRES, H.; ALBAGLI, S. (Org.). Informação e globalização na era do conhecimento. Rio de Janeiro: Campus, 1999.

14-LEONARD-BARTON, Dorothy. Nascentes do saber - criando e sustentando as fontes de inovação. Rio de Janeiro: Fundação Getúlio Vargas, 1998.

15-MYERS, P. S. (Ed.) Knowledge management and organization design. Butterworth-Heinemann, 1996.

16-NONAKA, I.; TAKEUCHI, H.; Criação de conhecimento na empresa. Rio de Janeiro: Campus, 1997. 358p.

17-POLANYI, M. The tacit dimension. Gloucester, MA, 1983.

18-SENGE, P. M. A. A quinta disciplina. 9.ed. São Paulo: Best Seller, 1990.

19-STEWART, T. Capital Intelectual; a nova vantagem competitiva das empresas. RJ: Campus, 1998.

20-TERRA, J. C. Gestão do conhecimento; o grande desafio 'empresarial: uma abordagem baseada no aprendizado e na criatividade. São Paulo: Negócio Editora, 2000.

21-THUROW, L. C. O futuro do capitalismo; como as forças econômicas de hoje moldam o mundo de amanhã. Rio de Janeiro: Rocco. 1997.

22-VASCONCELOS, M. C. R. L. Cooperação Universidade Empresa na Pós Graduação: Contribuição para a Aprendizagem, a Gestão do Conhecimento e a Inovação na Indústria Mineira. Belo Horizonte: Escola de Ciência da Informação da UFMG, 2000, 257p. (Tese, Doutorado em Ciência da Informação ) 
